\title{
Scientific Perspectivism in Secondary-School Chemistry Education
}

\section{Integrating Concepts and Skills in Chemical Thinking}

\section{Ilse Landa ${ }^{1} \cdot$ Hanna Westbroek ${ }^{1}$ (D) - Fred Janssen ${ }^{2} \cdot$ Jacqueline van Muijlwijk $^{3}$. Martijn Meeter ${ }^{1}$}

Published online: 7 August 2020

(C) The Author(s) 2020

\begin{abstract}
The importance of learning chemical ways of thinking is widely recognized. Various frameworks have been developed to address the essence of chemistry and chemical thinking. However, very few studies have focused on how chemical ways of thinking can be defined. To elaborate chemical ways of thinking, this paper draws on scientific perspectivism (Giere 2010; Wimsatt 2007; Thagard 2012). Scientific perspectivism states that, within each general domain, several broadly accepted theoretical models exist side by side. These general theoretical models, or theoretical perspectives, determine which research questions are generated, which types of models are developed, and which criteria are important for evaluating models. A theoretical perspective can be captured in a core reasoning that embodies the fundamental relationship between model and the "real world." Starting with their most basic form, perspectives can be used in learning how to reason about all types of ill-structured problems, directing and organizing knowledge development, and integrating knowledge and skills. The study is part of a research project on how perspectivism can be applied to the design of secondary-school chemistry education. This particular study concerns the identification, elaboration, and validation of four chemical perspectives for secondary-school chemistry education. We use these perspectives to indicate the consequences of taking a perspectivism approach to a curriculum framework. We conclude with discussing the consequences for secondary chemistry curriculum.
\end{abstract}

\section{Introduction}

In oder to help students address ill-defined authentic problems, international reforms in chemistry education increasingly emphasize the importance of learning chemical ways of

Hanna Westbroek

H.B.Westbroek@vu.nl

Extended author information available on the last page of the article 
thinking (NRC 2013; Sevian and Talanquer 2014; Van Berkel et al. 2000). Dominant teaching approaches in chemistry education do not sufficiently prepare students for this, as they are mostly centered around explaining and applying concepts instead of chemical questions that form the starting point for thinking processes (Sevian and Talanquer 2014). When a phenomenon is being investigated, chemical ways of thinking that represent the discipline, are thinking tools that define the problem space, the types of questions that are relevant, which types of answers are possible, and how these might apply specifically to the phenomenon at hand (Callebaut 2012). Developing chemical ways of thinking contributes to insight in the nature of chemistry, its power and limitations. For example, a chemistry student who does not know how the differences between diamond and graphite (which both consist of carbon) can be explained, but who has developed a certain level of chemical thinking, would be able to formulate the types of questions that are relevant to investigate, such as: "How are the particles bonded and organized in these particular substances?" Furthermore, the student could reason that part of the answer is probably that the chemical bonds between the particles of the two substances differ in nature and in strength.

What is still unclear, however, is how chemical ways of thinking can be defined, which is therefore the focus of this study. The lack of definition is manifest in current chemistry standards and Dutch secondary-school (pre-university) chemistry textbooks, which seem to focus either on chemical content or on general skills (e.g., Erduran 2007; Sevian and Talanquer 2014). With regard to content, chemistry curricula have been characterized as fragmented, topic-centered lists of concepts (Cooper et al. 2017; Gilbert 2006; Van Berkel et al. 2000), while skills are often described in such general terms that they could apply to each and every domain. How content and general skills are to be connected remains unclear. This fragmentation and the divide between content and skills is also apparent in most Dutch secondaryschool chemistry textbooks, in which each chapter tends to be an isolated unit of content illustrated by experiments.

Due to this failure to integrate content and skills - with regard not only to standards or objectives but also to methods and actual teaching practice - subject matter functions more or less as the context for learning "scientific practices." As a result, "the scientific method" tends in classroom settings to become a general one-size-fits-all procedure rather than a domainspecific way of thinking (Osborne et al. 2018; Windschitl et al. 2008). In this way, chemical reasoning is reduced to reasoning within a chemical context. However, there is a fundamental difference between knowing how to reason on the basis of a given argument - a general skill - and knowing how to construct and evaluate a valid chemical argument - a domainspecific skill that requires a chemical way of thinking. Learning chemical ways of thinking would at least involve a shift from learning chemical concepts - often in isolation - to learning to ask questions that reflect those chemical ways of thinking.

The lack of an adequate conceptualization of chemical ways of thinking is also apparent in various influential frameworks that have been developed over the years and have sought to capture aspects of chemical thinking in different ways and to different extents, such as "Big Ideas of chemistry (Atkins 2010)" and "threshold concepts (Talanquer 2015)." As we discuss below, we contend that, however valuable their contributions when we are thinking about problems, none of the frameworks coherently operationalize chemical ways of thinking as domain-specific thinking tools that scaffold knowledge search and knowledge development.

To elaborate chemical ways of thinking, this paper draws on scientific perspectivism (Giere 2010; Wimsatt 2007; Thagard 2012). In brief, scientific perspectivism states that, within each general domain, several broadly accepted theoretical models exist side by side. These general 
theoretical models, or theoretical perspectives, determine which research questions are generated, which types of models are developed, and which criteria are important for evaluating these models (Giere 2010). A theoretical perspective can be captured in a core reasoning (Thagard 2012) that embodies the fundamental relationship between model and the "real world." Starting with their most basic form, perspectives can be used in learning how to reason about all types of ill-structured problem, more fundamental, scientific problems, and also problems that concern applications such as drug design. They direct and organize knowledge development. As a consequence, theoretical perspectives integrate knowledge and skills, and can be developed as thinking tools (Janssen et al. in press).

In this paper, we discuss a study undertaken as part of a research project on how perspectivism can be applied to the design of secondary-school chemistry education. This particular study concerns the identification, elaboration, and validation of four chemical perspectives for secondary-school chemistry education. We use these perspectives to indicate the consequences of taking a perspectivistic organizer for the curriculum. This study therefore focuses on the following question:

What theoretical perspectives reflect chemical ways of thinking that are relevant to secondary chemistry education?

First, however, we discuss other, dominant frameworks that aim to address the essence of chemistry and chemical thinking: big ideas, threshold concepts, and styles of reasoning proposed by Kind and Osborne (2017). We include a discussion of the Next-Generation Standards (NGSS). Although this framework is not a framework for chemistry education, it includes the development of chemical concepts and is unique in the way it integrates conceptual understanding, understanding of general cross-cutting scientific concepts, and the development of scientific inquiry skills such as modeling and formulating hypotheses. Our aim is to show how all these frameworks contribute to aspects of chemical thinking but do not adequately operationalize chemical ways of thinking that students can develop as thinking tools.

Second, we discuss scientific perspectivism and its philosophical foundations, which form the theoretical base for the perspectivistic organizer for the curriculum that we propose. Next, we discuss the core of this paper: the four chemical perspectives for secondary-school chemistry education that we have identified, elaborated, and validated. Finally, we discuss the consequences of basing a secondary-school chemistry education curriculum on a perspectivistic approach. We conclude with some reflections.

\section{Big Ideas, Threshold Concepts, NGSS Standards, and Styles of Reasoning}

On the basis of the exemplary case of a theme that is at the core of chemistry- "structure and properties of matter"- this paragraph discusses how four dominant frameworks in chemistry education highlight different aspects of chemical ways of thinking but lack adequate conceptualization.

\subsection{Big Ideas}

There is general consensus that chemistry is in essence "the study of the nature, structure, and transformation of matter" (Gabbay et al. 2010; Weisberg et al. 2016; Zumdahl and Zumdahl 
2006). This consensus is apparent from the analysis of documents (Atkins 2010; Claesgens et al. 2009; Cooper et al. 2017; Gillespie 1997; Talanquer 2016) that identify central ideas in chemistry, and thereby testify to considerable agreement between authors on what, in conceptual terms, the study of the nature, structure, and transformation of matter entails (Table 1, see also de Jong and Talanquer 2015). All these documents describe analogous understandings about the atomic nature of matter, chemical bonding, molecular structure, structure-property relationships, chemical reactions, and reaction energetics and dynamics. The "big ideas" frameworks provide powerful structures for explaining the conceptual foundations of chemistry.

While "structure and property of matter" is sometimes elaborated as a "big idea" in itself (e.g., Talanquer and Pollard 2010), sometimes it is not. Atkins (2010) discusses nine chemical big ideas, three of which can be seen as in some way pertaining to structure and property of matter. In his view, the first of these - that matter consists of atoms - provides the basis of stoichiometry and quantifying chemical processes. The second idea is that elements form families that have certain properties; the elements that form families can be predicted by their electron configuration. The electron configurations have a rhythm that follows from their place in the periodic table. The third big idea is that atoms combine through shared electrons. This can result in covalent, ionic and metallic bonds. In comparison, Claesgens et al. (2009) used a framework of core chemical ideas to investigate the development of student understanding. While the framework is less detailed in the formulation of chemical concepts, it puts more emphasis on the relation between those concepts. An example of this can be seen in the way in which they describe the relationship between the microscopic properties of particles and the macroscopic properties of matter: "The composition, structure, and properties of matter are explained by varying strengths of interactions between particles (electrons, nuclei, atoms, and ions, molecules) and by the motions of these particles, and are related to how electrons are distributed among atoms" (Claesgens et al. 2009, pp. 70-71).

The examples show that while big idea approaches offer a conceptual unpacking of chemical core ideas, they do not provide additional clues for how these conceptual foundations of chemistry can be used to develop chemical ways of thinking in a chemistry class. A big idea does not specify as such which questions are relevant for studying a phenomenon, what type of explanation(s) is sought for, and how explanations can be integrated into a specific model that explains the phenomenon, or a hypothesis that guides further investigations. In addition, even though they are based on analogous understandings, the lists of big ideas differ in length and in their precise formulation. The big ideas also seem to be formulated on very different levels (see also de Jong and Talanquer 2015).

\subsection{Threshold Concepts}

Meyer and Land (2003) introduced the idea of threshold concepts in the context of economics education. Since their publication in 2002, the idea of threshold concepts has been embraced by many scholars from a range of disciplines. Threshold concepts are defined as central concepts in a discipline, that, among other things, are integrative; troublesome (difficult to understand and often counterintuitive); irreversible (cannot be unlearned); and transformative. The authors argue that threshold concepts are transformative in the sense that if students fail to understand threshold concepts, they cannot develop their domain-specific ways of thinking any further. Threshold concepts therefore form barriers not only to learning (troublesome) but also to potentially new ways of domain-specific thinking. Projects that emerged from this idea 
focus on identifying threshold concepts, and exploring the nature of the "troublesome knowledge" associated with these concepts. In the context of chemistry, Talanquer (2015) proposes that concepts such as "atomicity," "chemical bonding," "intermolecular forces," and "chemical equilibrium" can be considered threshold concepts.

With respect to the case of structure and property of matter, Talanquer (2015) explains that understanding atomicity is foundational for making sense of, predicting, and controlling the properties of matter. He then explores the conceptual, epistemological and ontological elements of "atomicity," and what might be the "troublesome knowledge" associated with this threshold concept. According to the author, the following conceptual ideas (amongst others) can be associated with the concept of atomicity: "Matter consists of atoms that have internal structures that dictate their chemical and physical behavior. Atoms have unique chemical identities based on the number of protons in the nucleus. Atoms display a periodicity in their structure and observable properties that depend on that structure." (Talanquer 2015, p. 4).

One troublesome idea that novices tend to have is that the properties of a material are the same at all scales, and that changes in the properties at the macro level are similar to changes in the properties at the submicroscopic level: "if a solid expands, its constituent particles also expand; if a substance changes color, its atoms or molecules do the same." (Talanquer 2015, p. 5).

Not surprisingly, threshold concepts that Talanquer (2015) proposes can be traced back to the lists of big ideas we discussed in the previous section (Table 1). What Meyer and Land (2003) and Talanquer (2015) add to the identification of big ideas is an explicit focus on what is (the nature of) troublesome knowledge (or potential learning difficulties, or alternative conceptions) that impedes the mastering of specific threshold concepts within a domain. Although information about the nature of troublesome knowledge is undoubtedly of great value to successful chemistry education, none of these authors elaborate further on the nature of the chemical reasoning that students could develop as thinking tools for addressing problems. Threshold concepts do not clarify which specific types of questions are relevant when investigating a phenomenon, nor the type of explanations that such an investigation would yield, and that can be used to for development of an explanatory model of the phenomenon at hand, or an hypothesis that needs to be investigated.

\subsection{Next-Generation Science Standards}

The Next-Generation Science Standards (NGSS) were developed as K-12 science content standards to improve science education in the United States (USA). The NGSS are not meant as a guiding framework for chemistry education in particular, but rather as a framework for teaching integrated science. However, we still want to discuss NGSS here, as the rather influential framework is unique in its aims to integrate conceptual understanding (which includes chemical concepts), understanding of general cross-cutting scientific concepts, and the development of scientific inquiry skills. Moreover, prominent undergraduate and secondary-school chemistry curricula are inspired by the NGSS framework (e.g., Stowe et al. 2019).

NGSS are founded on three equally important components. The first, disciplinary core ideas, are defined as "The key ideas in science that have broad importance within or across multiple science or engineering disciplines; as central, organizing concepts within a domain that form a key tool for understanding or investigating more complex ideas" (NGSS Lead States 2013). The second, practices, are described as follows: "Science and Engineering practices describe what scientists do to investigate the natural world and what engineers do to design and build 


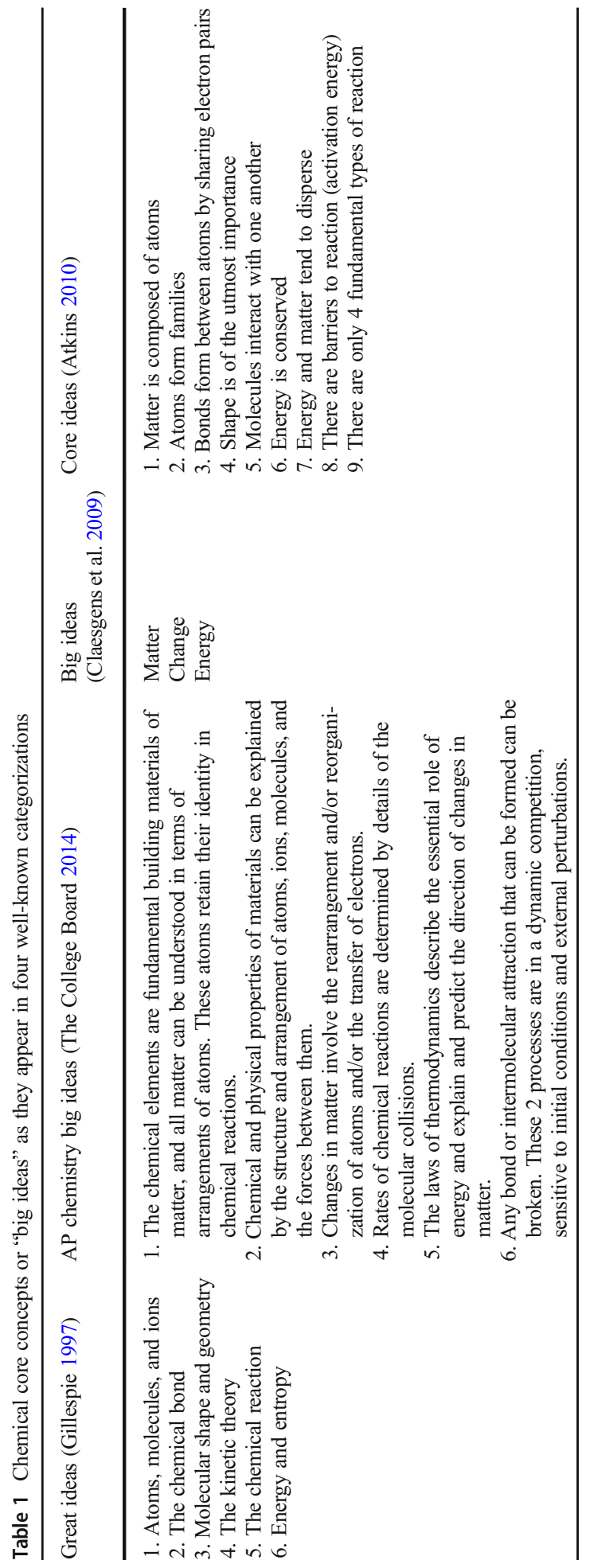


systems. The practices better explain and extend what is meant by 'inquiry' in science and the range of cognitive, social, and physical practices that it requires. Students engage in practices to build, deepen, and apply their knowledge of core ideas and crosscutting concepts" (NGSS Lead States 2013). The third, crosscutting concepts, are defined as "Concepts that, when made explicit to students, should enable them to see connections between science domains, and help them to develop a coherent scientific view of the world" (NGSS Lead States 2013). These three core components are arranged in so-called topics, such as "structures and properties of matter," and "energy." The standards are organized by topic, each combining core concepts, practices, and crosscutting concepts that belong to that particular topic. Although it is not explained how core concepts, practices, and crosscutting concepts are selected to form a standard, students are expected to use practices to demonstrate understanding of the core ideas.

If we look at the exemplary case of "structure and properties of matter" (a central topic in chemistry, fifth grade), two core ideas are listed: structure and properties of matter (i.e., the topic itself); and "chemical reactions." Crosscutting concepts that belong to this topic are "patterns," and "structure and function." Several practices are listed, such as "developing and using models." For structure and properties of matter, the following standards are formulated:

- Use the periodic table as a model to predict the relative properties of elements based on the patterns of electrons in the outermost energy level of atoms. (Clarification statement: examples of properties that could be predicted from patterns could include reactivity of metals, types of bonds formed, numbers of bonds formed, and reactions with oxygen.) (Assessment boundary: assessment is limited to main group elements. Assessment does not include quantitative understanding of ionization energy beyond relative trends.)

- Plan and conduct an investigation to gather evidence to compare the structure of substances at the bulk scale to infer the strength of electrical forces between particles. (Clarification statement: emphasis is on understanding the strengths of forces between particles, not on naming specific intermolecular forces (such as dipole-dipole). Examples of particles could include ions, atoms, molecules, and networked materials (such as graphite). Examples of bulk properties of substances could include the melting point and boiling point, vapor pressure, and surface tension.) (Assessment boundary: assessment does not include Raoult's law calculations of vapor pressure.)

- Communicate scientific and technical information about why the molecular-level structure is important in the functioning of designed materials. (Clarification statement: emphasis is on the attractive and repulsive forces that determine the functioning of the material. Examples could include why electrically conductive materials are often made of metal, flexible but durable materials are made up of long chained molecules, and pharmaceuticals are designed to interact with specific receptors.) (Assessment boundary: assessment is limited to provided molecular structures of specific designed materials.)

Not surprisingly, core ideas (and some crosscutting concepts) that pertain to chemistry can be traced back to what are considered "big ideas" (as discussed in Sect. 2.1) in the same way as the threshold concepts. Like threshold concepts, the NGSS add to the big ideas that attention is paid to aspects of the learning of chemistry. What the NGSS add to the threshold concept framework is that they are based on learning progressions and that they combine conceptual learning with the learning of scientific practices. For example, structure and properties of matter is built up from the second grade and starts by exploring and categorizing properties of matter. In this sense, the NGSS offer more guidance on the ways in which students can use and 
develop concepts in a learning progression and in concert with practices. On the other hand, the NGSS do not elaborate domain specific ways of chemical thinking as potential thinking tools for ill-structured problems. Conceptual learning and learning of scientific practices (argumentation, investigation) are separate domains in the NGSS, which conceptual content functions merely as a context for mastering scientific practices. The scientific practices that are selected, propose on a general level that a research question should be formulated about a certain phenomenon, or that a model should be developed of a phenomenon. Chemical ways of thinking as we envision in this paper, however, should offer students insight in the types of questions they can formulate to study a phenomenon, the types of explanations this will yield and how these can be integrated in the development of a model of the phenomenon or hypothesis about the phenomenon.

\subsection{Styles of Reasoning}

Kind and Osborne (2017) and Osborne et al. (2018) define styles of reasoning that emerge from analysis of scientific practices (based on Crombie 1994). They argue that styles of reasoning reflect the ontological, methodological, and epistemic diversity of the sciences. Osborne et al. (2018), p. 970) put forward six styles of reasoning, which, they argue, offer "a rationale for the content and an overarching view of the discipline and its intellectual achievements." The styles of reasoning all refer to the specific "ways of working"- such as "mathematical deduction," or "categorization and classification," and "hypothetical modeling" - that scientists employ when working on specific problems. In their view, such problems come down to three categories: What exists? Why does it happen? How do we know?

Although we found no worked-out example of structure and properties of matter, the authors offer the following example of how styles of reasoning can be addressed in class: "while studying evolution, the teacher can show how Darwin developed an evolutionary account that drew on the best inferences that could be made (abductive reasoning) from his observational data in the Galapagos. And while studying the periodic table the teacher can point to the fact that the act of categorization and classification has let to one of the major triumphs of science in the field of chemistry using inductive reasoning" (Osborne et al. 2018, p. 972).

Osborne et al. (2018) problematize the notion of "one scientific method for all," as not doing justice to the diversity and creativity of the sciences. In this sense, styles of reasoning informs science teaching by offering a more refined image of scientific practices. However, the problem of how chemical ways of thinking can be conceptualized still remains. Styles of reasoning refer to general ways of working, such as "categorizing" and "hypothetical modeling" that apply to all the natural sciences - and the framework is also intended as a basis for a coherent science curriculum. Chemical ways of thinking, however, refers to thinking tools that specifically belong to the domain of chemistry, and that guide "chemical categorizing" and "chemical hypothetical modeling." We contend that to solve chemical problems, such chemical ways of thinking are needed instead of more general science principles.

\section{Scientific Perspectivism}

Scientific perspectivism is an approach to understanding and representing knowledge development. It enables us to elaborate the role of perspectives in scientific thinking in 
general and chemical thinking in particular. Important proponents of scientific perspectivism are Giere (2010) and Wimsatt (2007). For an overview, see Kuipers (2007).

Scientific perspectivism can be understood as an attempt to escape from absolute forms of objectivism and relativism (Giere 2010). Like objectivists, representatives of scientific perspectivism assume that there is a reality that is independent of human knowledge construction. Perspectivists acknowledge, however, that our knowledge of reality is always incomplete and constrained by our perspectives: we cannot achieve a "view from nowhere." In this sense, proponents of scientific perspectivism agree with relativists that our knowledge is constructed. But this does not mean that "anything goes." First, scientific perspectivists argue that although perspectives themselves are not empirically testable, models based on perspectives are (Giere 2010). Second, while relativists assume that each perspective is complete and that all perspectives are therefore in competition, scientific perspectivists view perspectives as partial and incomplete. Complex situations always need to be viewed from multiple perspectives (Wimsatt 2007). Important scientific perspectives include the evolutionary perspective, the classical mechanical perspective, and the thermodynamic perspective.

To articulate scientific ways of thinking, perspectives have two very relevant features. The first consists of a variable-value structure that can be used to describe certain aspects of a situation (Wimsatt 2007; Thagard 2012). Consider this simple example of a perspective: a thermodynamic-perspective on chemical reactions. The way of thinking based on this perspective can be articulated in the following core explanation pattern:

- Explanation target:

Why do some reactions go to completion while others do not under certain conditions?

- Explanation pattern:

The extent to which a process unfolds under certain conditions depends on the relation between enthalpy changes and entropy changes.

The words in bold are variables (placeholders) that can take multiple values. For instance, several classes of reactions have been discovered that unfold in different ways, depending on the conditions. In turn, these values can be seen as variables that can take multiple values. For instance, several examples of reactions can be distinguished. This brings us to the second important feature of a perspective: As a result of this so-called recursive variables-values structure, a perspective has a hierarchical character, and, as such, provides an advance organizer for developing knowledge from this particular perspective. Hundreds of chemical reactions can be organized with this thermodynamic perspective.

The variable-value structure of perspective, and the way of thinking related to it, can also be represented in a question agenda that scaffolds knowledge search (Love 2013). In this case, the variables can be reformulated in the following question agenda:

- Which reaction(s)?

- What are the conditions?

- What is the entropy change?

- What is the enthalpy change?

- What is the relationship between enthalpy change and entropy change? 
A perspective can thus scaffold knowledge seeking by breaking down a principle question into multiple (related) sub-questions in such a way that the answers developed for the sub-questions can be assembled into an answer to the principal question. In most complex cases, this deconstruction down comes in stages. Sub-questions in turn split into consecutive auxiliary questions (Which type of reaction? Which reaction?) showing the hierarchical character of the perspective. In this way, a perspective helps to reduce stepwise the search space or problem space for information that solves the problem (Hintikka 2007; Rescher 2008; see also Love 2013; Brigandt 2013 for the central role of a problem agenda or "question agenda" in both scientific practice and science education).

The function of such question agendas is comparable to the game, in which one has to find out in as few questions as possible what a person is thinking about (Rescher 2008; Love 2013). Because such a variety of answers is possible, it makes no sense just to guess along. Rather, it is important, through a stepwise approach, to efficiently reduce the search or problem space as much as possible. You can do this by starting with broad categories, such as "is it alive or dead?". If it is alive, you can ask whether it is a plant or an animal. With each new question, you get new information that enables you to ask the next, more specific, question. This movement from general to specific is similar in scientific research. A perspective defines the types of question and answer you look for at a certain level of abstraction.

In sum, perspectives scaffold the articulation of questions and the process of finding and validating answers. At the same time, reflection on the knowledge that develops in this way can result in changes in the perspective. First of all, knowledge development can lead to differentiation of a perspective (Giere 2010; Thagard 2012; Ohlsson 2013): for certain variables new values can be discovered. In turn, it can be discovered that values are variables in themselves that can take multiple values. This way, a perspective can develop as a hierarchical question agenda that develops new branches again and again.

In conclusion, a theoretical perspective both conceptualizes domain specific ways of thinking and provides a hierarchy for individual concepts. As such, theoretical perspectives represent ways of thinking and might prove to be excellent organizing principles for curricula in general, and, in this case, the chemical curriculum.

\section{Development and Validation of Theoretical Perspectives for Secondary-School Chemistry Education}

The aim of this study is to identify theoretical perspectives that are relevant for secondaryschool chemistry education and that embody chemical ways of thinking. A perspective can be regarded as an operational footing for existing chemical thinking patterns. These thinking patterns are explained in the form of core reasonings (explanation patterns) and question agendas, as we explained in the previous section.

We identified and validated four chemical perspectives in three steps:

- Step 1 Bottom-up identification of distinct chemical perspectives that experts use.

First, a group of six chemistry experts were invited to reason about phenomena that we derived from the Dutch secondary-school (pre-university) chemistry curriculum syllabus. Every year, the ministry of education publishes for each school subject the standards, to be assessed in the final, central examinations (Sect. 4.1). We analyzed the experts' reasonings for reoccurring 
patterns in the concepts that they applied. Our aim was to identify which distinct theoretical orientations or perspectives the experts in fact applied in these concrete examples. Four chemical perspectives were identified by the authors, and validated by the experts. Next, the theoretical perspectives were refined by elaborating them as core reasonings and accompanying hierarchical question agenda's, which were, again, validated by the experts.

- $\quad$ Step 2 Theoretical validation of the chemical perspectives

Next, we conducted a theoretical validation of the four chemical perspectives that emerged in step 1, by mapping to the perspectives what various influential scholars have identified as the big ideas in chemistry and the nature of chemistry (Sect. 4.2). Our aim was to verify whether the chemical perspectives "covered" all the big ideas.

- Step 3 Empirical validation of chemical perspectives that are relevant for secondary-school chemistry.

Finally, to validate the relevance of the four chemical perspectives for secondary-school chemistry education, we established the extent to which five secondary-school chemistry teachers applied the four chemical perspectives in their reasonings about why-questions (Sect. 4.3).

\subsection{Identification of Chemical Perspectives}

First, as our aim was to establish chemical perspectives that are relevant for A-level chemistry, we invited a group of chemistry experts to reason about why-questions that were derived from concepts belonging to the Dutch secondary-school (pre-university) chemistry curriculum syllabus (see A. Development of Why-Questions). When analyzing their reasonings, we searched for reoccurring patterns that could be categorized as belonging to the same distinct general chemical theoretical perspective. A theoretical perspective, such as a thermodynamic perspective, puts forward which concepts are relevant, and how concepts are related. Hence, taking a thermodynamic perspective on a phenomenon generates specific questions and reasonings. Then, in an iterative process of analysis and validation, we articulated perspectives as core reasonings and question agendas (cf. Thagard 2012) that represented the chemical ways of thinking the experts had in fact used in their reasonings about the phenomena.

The following experts were involved in this phase of identifying and then validating chemical perspectives: a professor from our department of chemistry who specializes in chemical drug design, two secondary-school chemistry teachers with a $\mathrm{PhD}$ in chemistry who specialize in biochemistry, an academic teacher of chemistry education $(\mathrm{PhD})$, and two higher education teachers and researchers in our chemistry department (both $\mathrm{PhDs}$ ) who specialize in thermodynamics and kinetics.

Development of Series of "Why-Questions" To facilitate the reasoning, we used the Dutch secondary-school (pre-university) exam program as a basis for developing a series of whyquestions that were within the scope of secondary-school chemistry standards. Most whyquestions sought an explanation of a common concept (e.g., Why does an acid donate a proton to a base? Why do substances dissolve in water?). Although chemistry programs differ slightly between one country and another, the general structure of school chemistry at an international 
level is remarkably consistent (Van Berkel et al. 2000). Table 2 provides an overview of ten common concepts, and how they are specified in the Dutch chemistry program. Entropy, Gibbs free energy, reaction order, and orbital hybridization are examples of topics that are not included in the Dutch program but are present in some curricula elsewhere (e.g., Cambridge International Examinations 2016).

Analysis of Expert Reasoning With Table 2 as the basis, the first author developed an exhaustive list of why-questions that were subsequently discussed by the group of experts. While discussing the "why" questions, the first author noted the concepts and models that the experts applied in their reasonings (e.g., in response to the question why a substance solves in water, the experts' reasonings would encompass the relative strength of the chemical bonding between the particles and changes in the Gibbs free energy). The first authors discussed her findings with the experts. On the basis of their reasonings and the theoretical models that were central in them, the experts and the first author identified what can be seen as distinct ways of chemical reasoning or perspectives that they had used to approach the questions on a general level.

The cycle of reasoning about why-questions and analysis of what are underlying, distinct chemical perspectives that were used in those reasonings was pursued with the experts in several sessions, until we could identify no new theoretical perspectives or think of any questions that led to other theoretical perspectives. Differences in opinion were discussed and investigated extensively until agreement was reached. For example, we explored the possibility of considering the valence-shell-electron perspective as an extension of the particle perspective. This led us to following a line of reasoning that involved the question "What is matter made of?" that made it seem logical to extend the micro level of particles to the sub-micro-level of electrons and protons. Eventually, because the particle perspective and the valence-shell-electron perspective both yield very distinct reasonings, thereby answering different types of questions, we rejected a combination of the two perspectives. While the particle perspective explains how properties of matter are related to the aspects of matter on a microscale, the valence-shell-electron perspective explains reactivity and the strength of forces between and within particles. To give a more concrete example, the particle perspective connects e.g., electric conductivity to the presence of charged particles within matter, while the valence-shell-electron perspective explains why these charged particles can exist.

Another subject of debate concerned the relationship between the kinetic perspective and the thermodynamic perspective, which were thought to have some overlap: They both encompass aspects of probability (chance of collision versus entropy) and of energy (activation energy versus reaction enthalpy). Although a combined "thermo-kinetic" perspective was constructed, it met with a lot of resistance when discussed by the experts in the field. They argued that both theories address very different types of problems: While kinetics explain how fast a reaction or process will unfold, thermodynamics explain the extent to which it will do so. Combining both theories in one perspective would do no justice to the historical development of these two fields of research and to the genuine differences in explanation patterns.

In conclusion, the experts' analysis of reasoning patterns showed that they constantly reverted to one of the four distinct theoretical models or perspectives, which we will henceforth refer to as (1) the particle perspective, (2) the valence-shell-electron perspective, (3) the thermodynamic perspective, and (4) the kinetics perspective. Some illustrative examples of why-questions and possible reasonings and how these were linked to the four theoretical 
perspectives are given in Table 3. Of course, most questions (such as question 1) can be approached from more than one perspective; in the expert discussions, these different possibilities were explored extensively.

Formulation of Core Reasonings and Question Agendas A guiding principle for the establishment of what can be considered a chemical perspective is that the perspective can be represented as core reasoning and accompanying hierarchical question agenda. Therefore, in a next step, the first author formulated the essence of each of the four perspectives as a single statement, a core reasoning. The core reasonings constituted a basis for the development of the question agendas (see thermodynamics example in Sect. 3) (see Table 4). Again, the core reasonings and question agendas were discussed and refined by the expert group, thinking back and forth between perspectives and whyquestions, until an agreement was reached. Sometimes, this resulted in a core reasoning that went beyond the current secondary-school chemistry curriculum. For example, all members of the group agreed that, without the concept of entropy, chemical equilibrium cannot be explained satisfactorily from a thermodynamic perspective. They also agreed that, at a basic level, it is possible to explain the concept of entropy to secondary-school pre-university chemistry students.

In other cases, the expert group concluded that it was necessary to simplify one of the perspectives. For instance, it was decided to restrict the valence-electron-shell perspective to the noble gas configuration (octet rule), although the boundaries of this simplified model are quickly met. But the level of thinking and mathematical skills required to really understand the next step is so abstract that we judged it to be beyond the scope of secondary-school chemistry. The basic core reasoning can also be made without this elaboration.

Table 4 provides an overview of the four perspectives, the core reasonings, and the accompanying sets of question agendas.

Table 2 Ten common concepts were identified on the basis of an analysis of the Dutch A-Level chemistry curriculum

\begin{tabular}{ll}
\hline Concept & Specification (as elaborated in the Dutch A-level standards) \\
\hline Nature of matter & $\begin{array}{c}\text { Bohr's atom model; noble gas configuration; molecules, } \\
\text { metals, salts; properties of matter }\end{array}$ \\
Stoichiometry & Conservation of atoms; Avogadro's number; molar gas \\
& volume \\
Kinetics & Colliding particles model; $E_{\mathrm{act}}$ \\
thermodynamics & Heat of reaction; Hess's law \\
Acid base chemistry & pH; strong and weak acids and bases; $K_{\mathrm{a}}, K_{\mathrm{b}} ;$ acid-base \\
& reactions; buffers \\
Redox chemistry & Redox reactions; corrosion; standard electrode potential; \\
& electrolysis \\
Organic chemistry & IUPAC nomenclatura; stereochemistry; Lewis structures; \\
& VSEPR; reaction mechanisms; polymers \\
Equilibrium & Equilibrium constant; disturbed equilibrium \\
Biochemistry & Sugars; lipids; proteins and enzymes; RNA, DNA \\
Analytical chemistry & Chromatography; mass spectroscopy \\
\hline
\end{tabular}

The "specification" column shows how they are specified in the current Dutch secondary-school (pre-university) standards overview (published annually at examenblad.nl) 


\subsection{Validating Theoretical Perspectives Using Literature}

To ensure that the four theoretical perspectives were not a feature only of Dutch secondaryschool chemistry, but were indeed anchored in academic chemistry internationally, we compared the four theoretical perspectives with core concepts and big ideas that have been described in literature, (as discussed in Sect. 2.1).

Table 5 lists four well-known overviews of core ideas connected to the four theoretical perspectives. As a first step, the first author reviewed the literature on chemical core ideas (see also Sect. 2.1) and checked for each of the core ideas in Table 5 (e.g., "Matter is composed of atoms," Atkins (2010)) if they could be considered pertaining to one of the four identified chemical perspectives (e.g., the particle perspective "The properties of substances can be explained by the nature of the particles of which it consists, the forces between them, and the movement and organization of those particles."). Findings were discussed with the second and fourth authors. We concluded that the big ideas of chemistry can all be traced back to the four theoretical perspectives identified, as indicated typographically in Table 5, and that no new perspectives emerged. Any differences lie in the representation of these ideas and the emphasis on certain concepts.

\subsection{Validating Theoretical Perspectives from a Chemistry Teacher's Perspective}

As a final validation of the four perspectives, we repeated the exercise we did with the expert group with five secondary-school chemistry teachers. In a semi-structured interview (first author), each teacher was interviewed at their school (1-2 h) and presented with a sequence of conceptual questions and was asked how he or she would explain these concepts in the classroom. It was emphasized that they did not have to stick to the boundaries of the current curriculum (in other words, they could give what they considered to be the most appropriate chemical reasonings for their students to develop). The teachers were pressed to give an explanation of the phenomenon that was as complete as possible and explained not only what the phenomenon encompasses, but also why it exists. The interview was recorded and transcribed. The first author analyzed the teachers' reasonings using the four theoretical chemistry perspectives as a framework, in order to establish which perspectives they used. Results were checked and discussed with the second author.

Table 6 provides an illustrative selection of the reasonings teachers gave us in response to our questions. Most concepts (six) are explained consistently from a single theoretical perspective. Other, solubility, structure and equilibrium, were approached from different perspectives. All teachers stated that they did not always offer the best explanation in the classroom because it took up lesson time and "the curriculum does not demand this type of reasoning." The use of rules of thumb is exemplary for this (Table 6). By offering rules of thumb (e.g., the Principle of Le Chatelier), students can get "correct answers" by simply applying those rules, without the need for further reasoning.

The interviews confirmed that secondary-school chemistry teachers used the same four theoretical perspectives that our research group did. No additional perspectives were identified. 


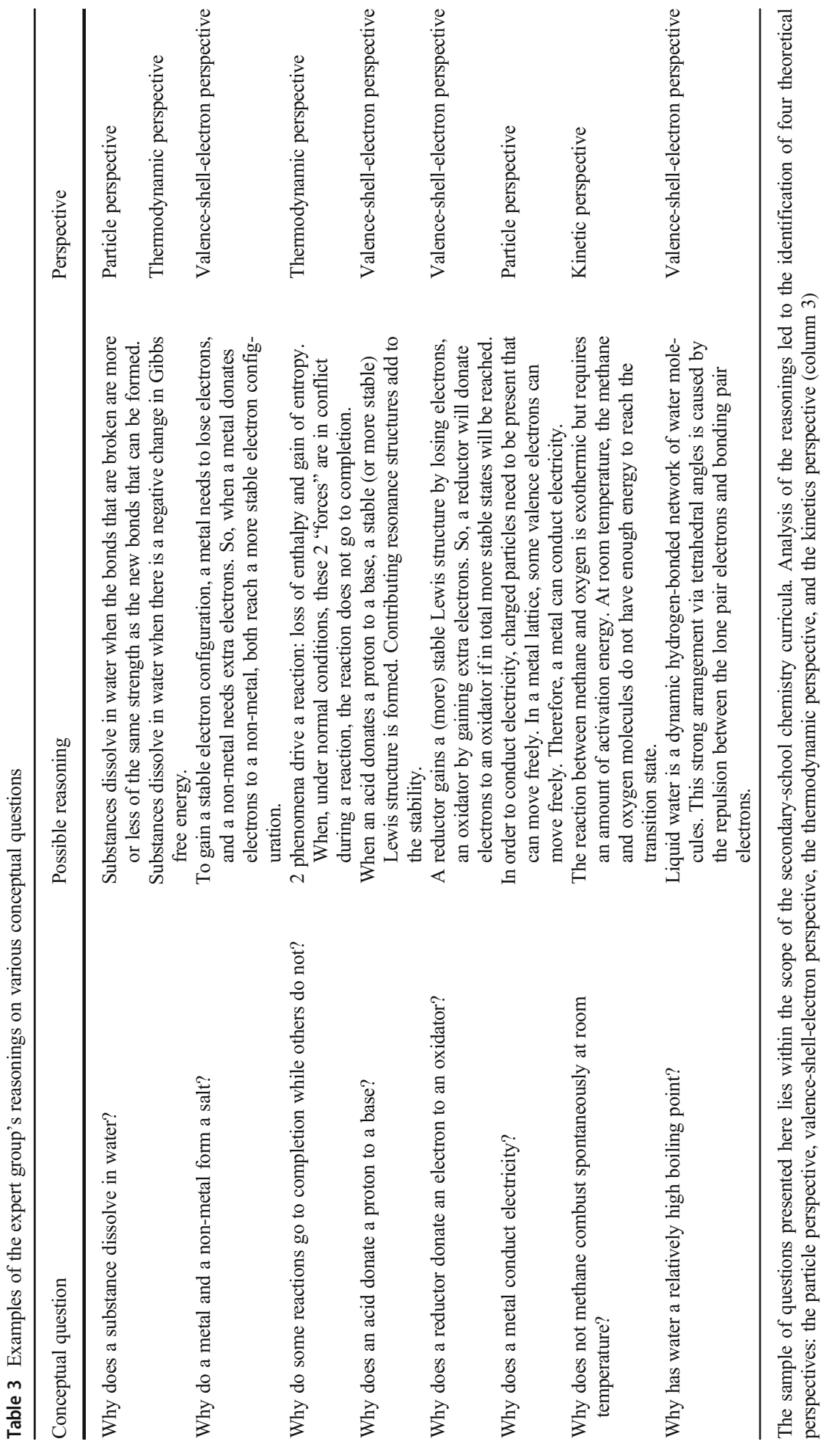


Table 4 The four core reasonings and respective question agendas of the particle, valence-shell-electron, thermodynamic, and kinetic perspective

\begin{tabular}{|c|c|c|}
\hline $\begin{array}{l}\text { Theoretical } \\
\text { perspective }\end{array}$ & Core reasoning & Question agenda \\
\hline Particle & $\begin{array}{l}\text { "The properties of substances can be } \\
\text { explained by the nature of the } \\
\text { particles of which it consists, the } \\
\text { forces between them, and the } \\
\text { movement and organization of } \\
\text { those particles." }\end{array}$ & $\begin{array}{l}\text { What property? } \\
\text { Which substance? } \\
\text { Which conditions? } \\
\text { What is the nature of the particles? } \\
\text { What are the forces between the particles? } \\
\text { How do the particles move? } \\
\text { How are the particles organized? }\end{array}$ \\
\hline Valence-shell-electron & $\begin{array}{l}\text { "(New) bonds and forces between and } \\
\text { within particles arise from } \\
\text { (re)arrangements of valence elec- } \\
\text { trons within and between particles. } \\
\text { These rearrangements can be un- } \\
\text { derstood by a combination of the } \\
\text { Lewis structure, shape of the } \\
\text { particles, and the electronegativity } \\
\text { of the atoms." }\end{array}$ & $\begin{array}{l}\text { What particle? } \\
\text { What (new) bonds and forces are being } \\
\text { formed? } \\
\text { What stable Lewis structures are possible? } \\
\text { What is the shape of the particle (VSEPR)? } \\
\text { How are de electrons distributed within the } \\
\text { particle (electronegativity)? }\end{array}$ \\
\hline Thermodynamic & $\begin{array}{l}\text { "The extent to which a process unfolds } \\
\text { under certain conditions depends of } \\
\text { the relation between enthalpy } \\
\text { changes and entropy changes." }\end{array}$ & $\begin{array}{l}\text { What are the conditions? } \\
\text { To what extent does the process unfold? } \\
\text { How does the enthalpy change? } \\
\text { How does the entropy change? } \\
\text { What is the relationship between enthalpy } \\
\text { change and entropy change? }\end{array}$ \\
\hline Kinetic & $\begin{array}{l}\text { "The velocity of a chemical reaction is } \\
\text { determined by the concentration of } \\
\text { the reactants, the activation energy, } \\
\text { the temperature, and the chance that } \\
\text { the reactants collide at the right } \\
\text { angle." }\end{array}$ & $\begin{array}{l}\text { What are the concentrations of the reactants? } \\
\text { What is the activation energy? } \\
\text { What is the temperature? } \\
\text { What is the chance that the reactants collide? } \\
\text { What is the chance of a collision in the right } \\
\text { angle? }\end{array}$ \\
\hline
\end{tabular}

\subsection{Summary}

We identified and validated four distinct chemical perspectives that are relevant to secondaryschool chemistry education. Between them, the particle perspective, the valence-shell-electron perspective, the thermodynamic perspective and the kinetic perspective substantiate all the key concepts of the curriculum.

All four perspectives are recognized and used —implicitly or otherwise — by experts and secondary-school chemistry teachers. As each perspective offers fundamentally different ways of approaching problems, they are complementary. Problems can be analyzed from different perspectives that will yield alternative or complemental explanations or hypotheses to explore. For example, the fact that substance A does not react with substance B at room temperature can be approached and partly explained from each of the four perspectives.

In the next section, we discuss how the four chemical perspectives can function as organizers for the chemistry curriculum, in a way that puts chemical ways of thinking into practice. In such a curriculum, students start by developing basic core reasonings and question agendas that evolve over time. 


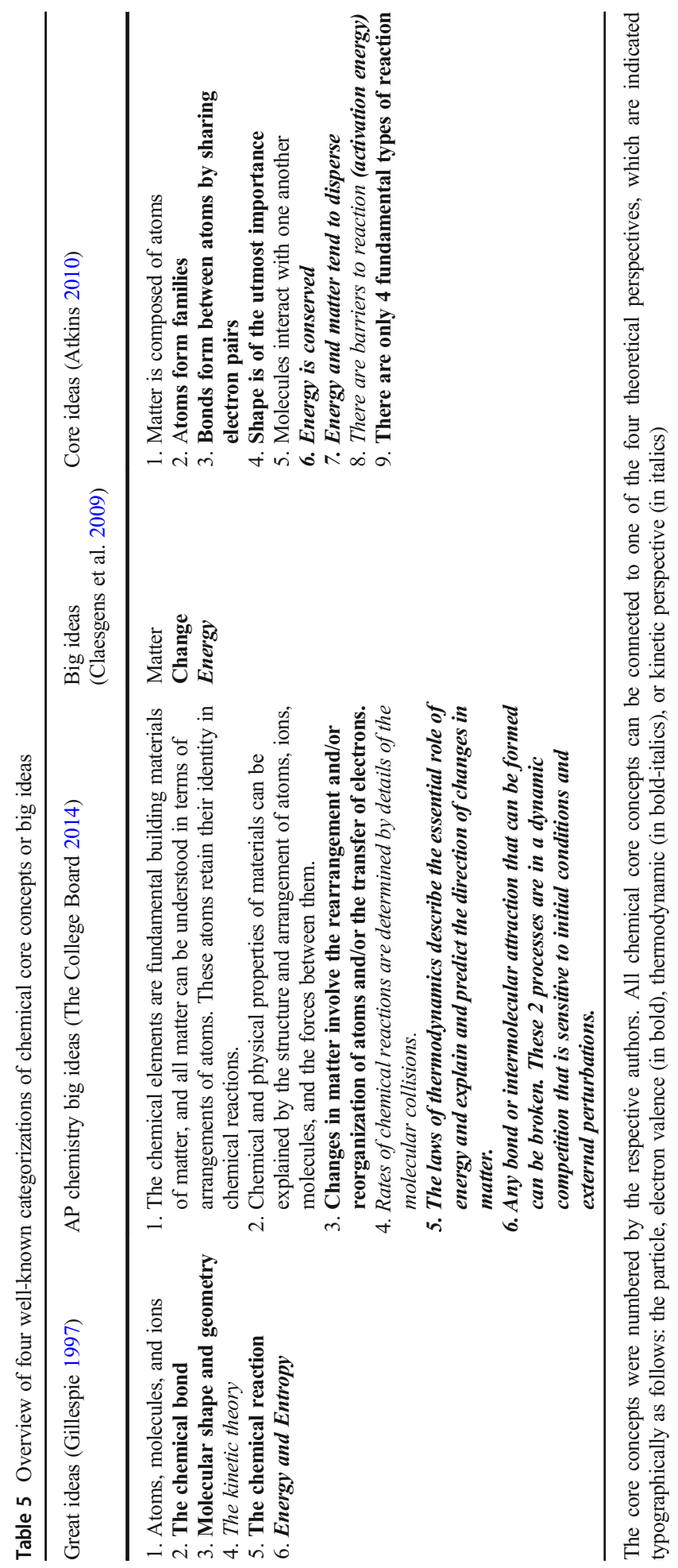




\section{Chemical Perspectives as Organizers for the Chemistry Curriculum}

To discuss the potential of using perspectives as thinking tools for approaching problems and how chemical content and practices become integrated this way, we use illustrative cases that belong to the particle perspective. We want to emphasize, however, that these cases are illustrative, as our main aim is to show the potential of basing a chemistry curriculum on chemical perspectives. Further research is needed to develop suitable pedagogies that support students with developing such perspectives as thinking tools, as we will point out in the discussion. Additionally, we illustrate how chemical perspectives create hierarchy and order in chemistry standards.

A perspective's question agenda can be visually represented as a hierarchy of questions that represents the lines of reasoning. Figure 1 represents the basic version of this question agenda.

As the different "branches" of the question agenda for the particle perspective support the theoretical exploration of phenomena, it is possible to integrate various scientific practices, such as modeling, and the formulation of research questions and theoretically based hypotheses. This is illustrated in the following examples.

Example 1: Detailed Analysis of Divergent Cases As solid water floats on liquid water, it must have a lower density rather than a higher density, which is normally the case. Density is determined by the mass of the particles (nature of particles) and how closely they are packed (organization). This must imply that the particles in the solid phase of water are organized such that - relative to the liquid phase - a fixed volume contains fewer molecules (organization). Can this be the case? Although the strength of intermolecular forces decreases with increasing distance, the particles in the solid state of water are held together more strongly than in the liquid state. What would be a model for the organization of the water molecules in the solid phase that fits the observations?

Example 2: Analysis of Experimental Results Conductivity experiments with metals, salts, and molecular substances in different phases can trigger reasoning about differences in the nature of particles and can lead to a model of substances that consist of charged or neutral particles (nature of particles) that can or cannot move (movement). A dataset of the boiling points and molecular masses of substances with and without a hydroxyl-group could be used to trigger to hypothesize about the existence of an additional type of force that must be stronger than the van der Waals force (type of force).

Example 3: Reasoning About III-Defined Problems This example is an excerpt from a discussion between a group of three students (16 years old) (from Janssen et al. in press) It is intended to illustrate how the particle perspective could function in class. The students were given the following problem: "Diamond and graphite both consist of carbon atoms. However, the properties of both materials differ enormously: for example, diamond is very hard, whereas graphite is soft. How can you explain this difference?" To support the discussion, the basic form of the particle perspective (Fig. 1) was drawn on the blackboard. The example shows how the students' reasoning enabled them to move towards the hypothesis that the bonds between the $\mathrm{C}$-atoms in diamond must be stronger than the bonds between $\mathrm{C}$ atoms in graphite, and, as the particles are the same, that this must mean that the $\mathrm{C}$-atoms in diamond are connected through double or even triple bonds. This hypothesis is subsequently "tested" when the teacher asks them to draw the carbon atoms in diamond. 

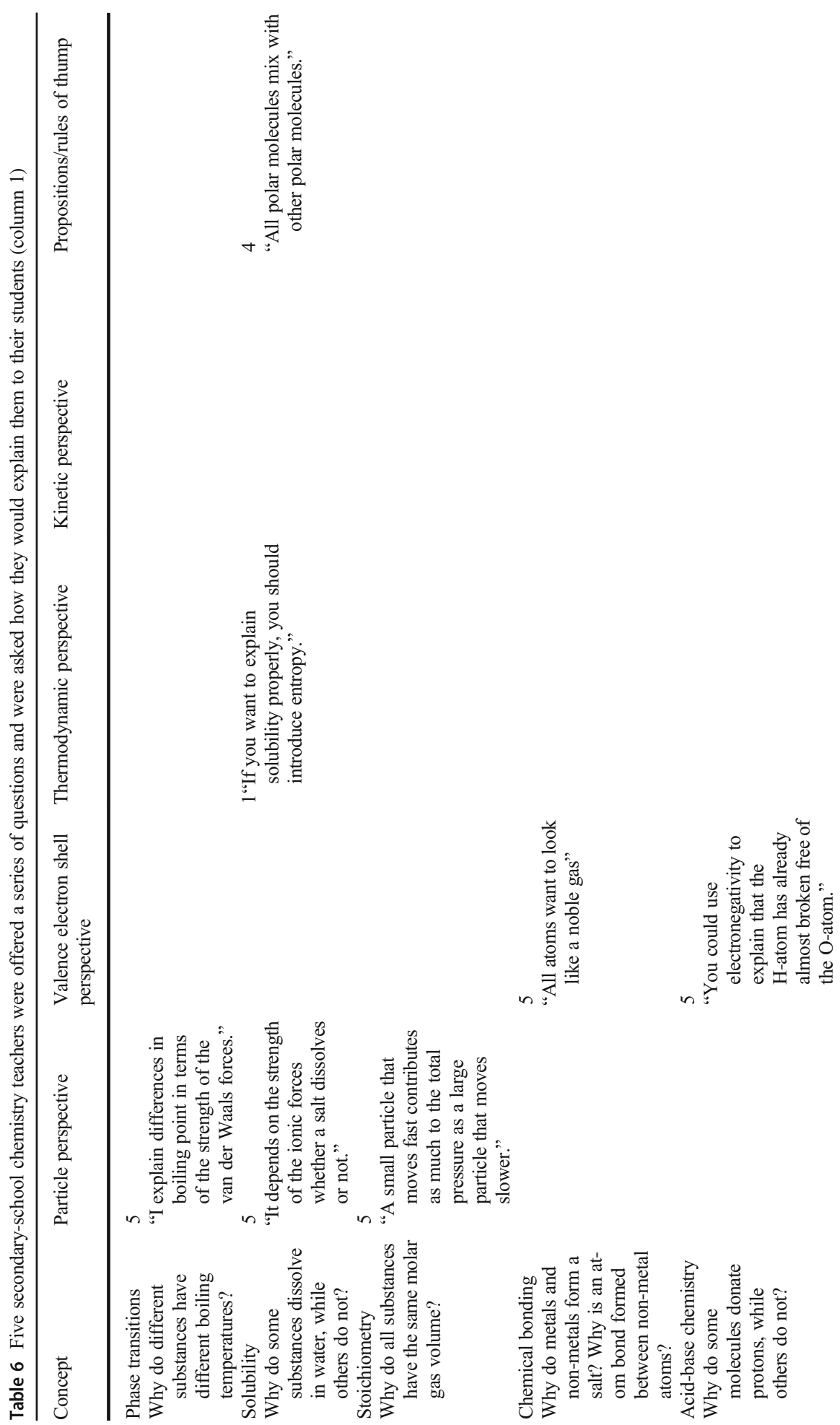


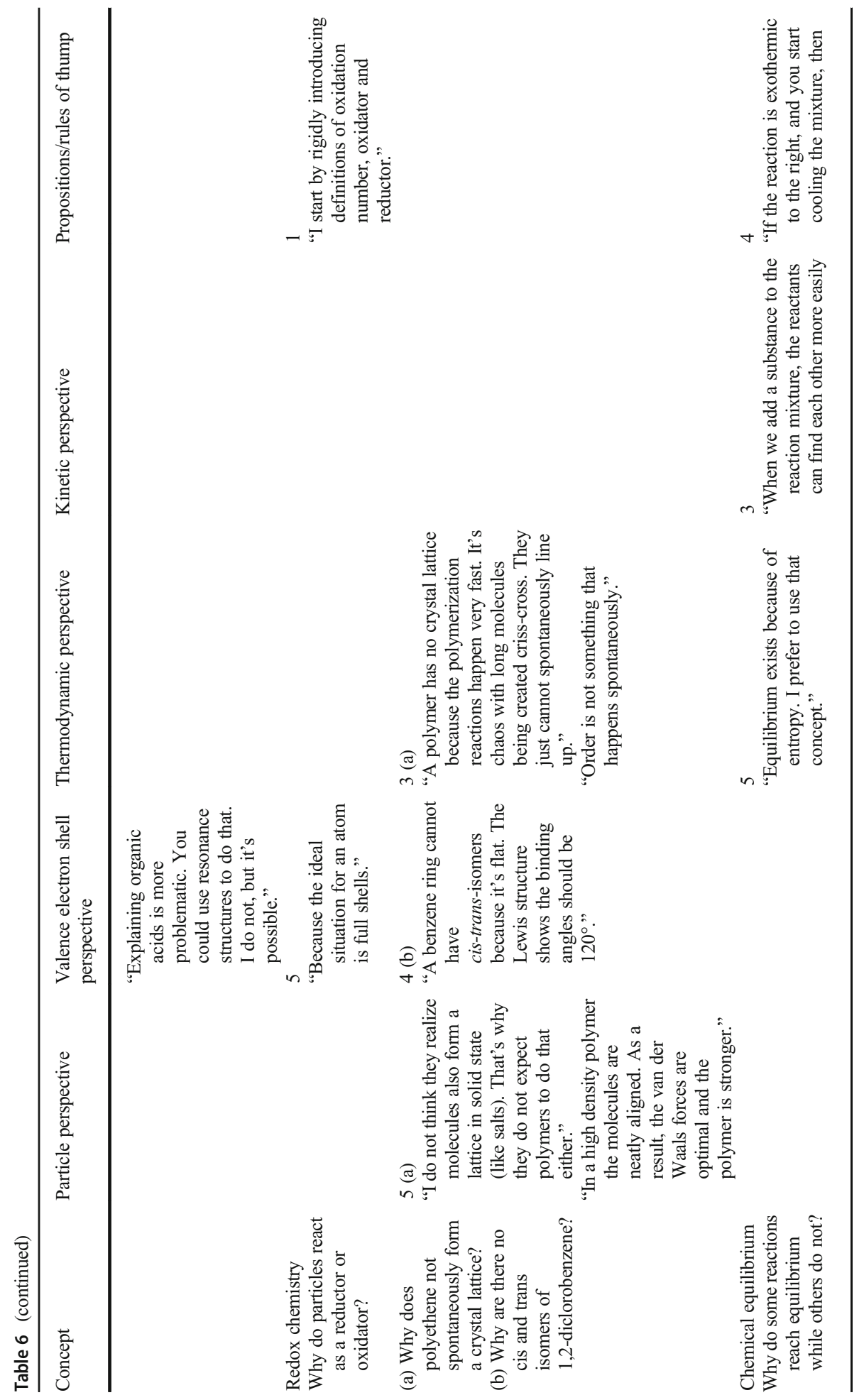




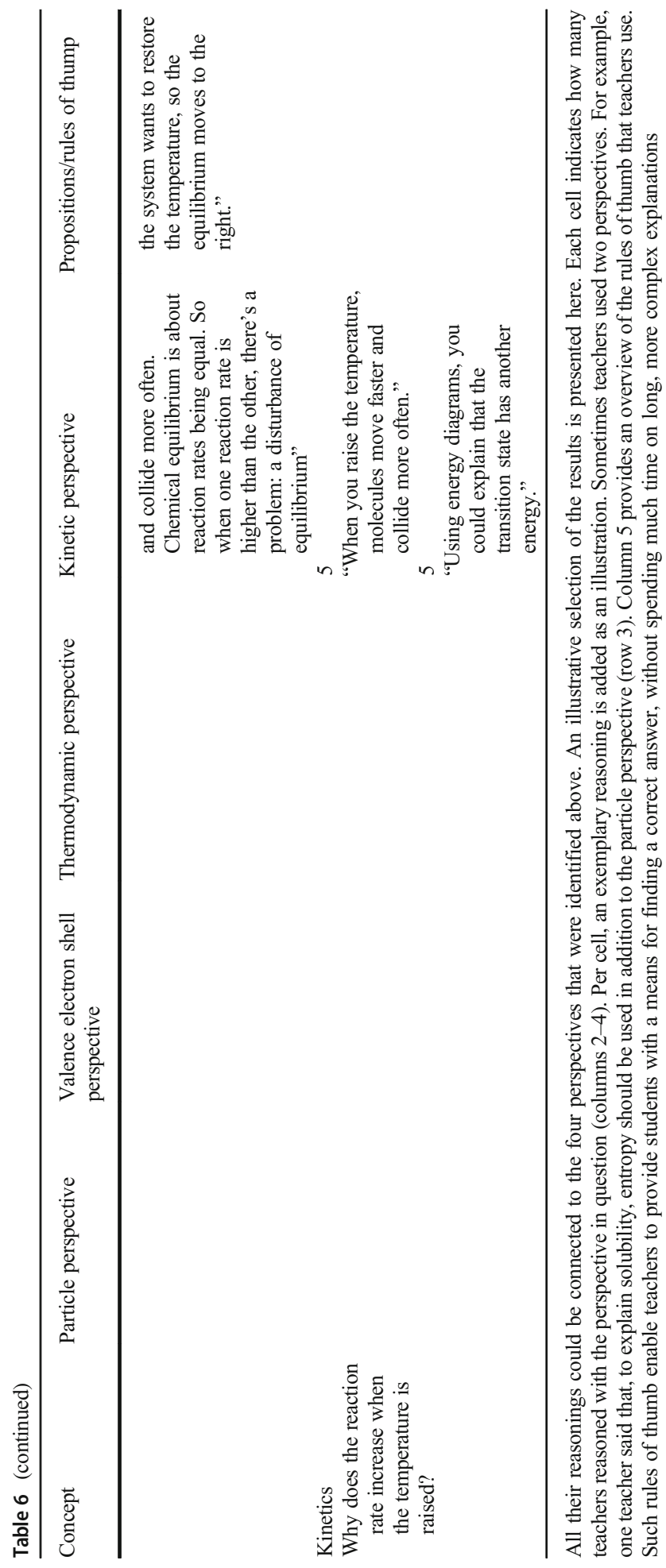


$(\mathrm{T}=$ teacher $/ \mathrm{S}=$ student $)$.

$\mathrm{S} 1$ : The nature of the particles is the same: all C-atoms.

S2: The bonds should be different, so there should be another structure, too.

$\mathrm{S} 1$ : Diamond is harder, so the bonds are stronger. Graphite has weaker bonds, so the material breaks off more easily.

S3: Which bonds are strong? Ionic bonds? Oh no - that's stupid: both materials are molecular. There can't be ionic or metal bonds.

S1: Can you melt diamond?

S2: Perhaps it's like coal: one big molecule.

S3: Diamond doesn't look like carbon.

S1: Okay, let's focus on the bonds.

S2: Graphite must be organized in something more like rows, like a metal, you can shove off a layer, not like with a salt.

S3: Diamond can be a lattice, a crystal lattice - that's why it is so strong.

S2: But does that mean a different bond or a different organization?

S1: How could there be different bonds?

S2: Single bonds or double atomic bonds?

S2: So in diamond, all atoms are linked with double bonds.

T: Could you draw that option?

S2: [Draws]

S1: No, that's not good, you only make a very long molecule, not a crystal. I don't think triple bonds would work either.

S3: I think there should be more symmetry. It should have something to do with difference in bond strength.

T: Why didn't you consider van der Waals forces?

S1: I didn't think carbon atoms could form molecules.

The examples illustrate how, by reducing problem space, question agendas scaffold the search for knowledge. On several occasions during the discussion, the students revert to the question agenda (Which bonds are strong?) and consider their options (There cannot be ionic or metal bonds.). The question agenda thus brings structure to an ill-defined problem. By pursuing the questions that belong to a perspective, perspective-specific knowledge is developed, and scientific practices such as modeling, developing research questions and hypotheses become integrated into the thinking process. This process can lead to a further extension and refinement of the question agenda (see Fig. 2 for an extended version of the particle perspective). Hence, in a perspective-based chemistry curriculum, the focus shifts from learning concepts and learning how to apply them, to using perspective-based question agendas as generative thinking tools that students can use to investigate problems, and further refine and develop in the process.

Finally, basing the chemistry curriculum on perspective development also creates a hierarchical order in chemistry concepts (see Fig. 2). Current chemistry curricula standards generally consist of lists of general skills (e.g., reasoning skills) and fragmented lists of concepts. Rather than fragmented, topic-centered lists of concepts, the perspective shows how these concepts are interconnected as parts of an explanatory model. Chemistry standards can now be determined by the extent to which the question agendas are elaborated and refined, while the core reasoning of the perspective at hand remains the same.

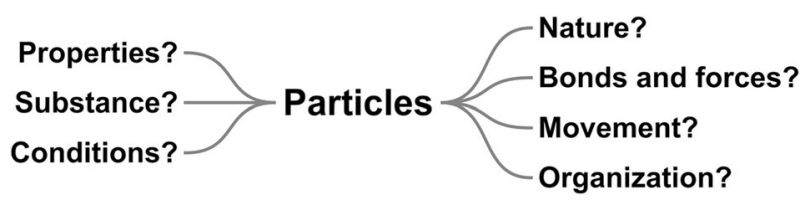

Fig. 1 Representation of the lines of inquiry of the particle perspective in its basic form. The properties of substances can be explained by the nature of the particles it consists of, the forces between, the movement of, and the organization of those particles 
Figure 3 represents this hierarchical way of organizing and connecting concepts. The question agendas constitute the lines of inquiry belonging to the respective perspectives. Education should always start with the basic questions and the core reasoning, such as those explaining how certain properties are connected to certain aspects of the particle model. Later, the model can be refined, introducing different kinds of particles, intermolecular forces, types of organization. These higher-order concepts will then have instant meaning, as they are linked to the underlying perspective.

\section{Discussion}

Although it is important to develop chemical ways of thinking, these ways of thinking are not properly conceptualized in current chemistry curricula and frameworks discussed in Sect. 2. In this paper, we explored the framework of scientific perspectivism as a foundation for elaborating chemical ways of thinking, and identified four chemical perspectives that are relevant to secondary-school chemistry: the particle perspective, the valence-shell-electron perspective, the kinetics perspective and the thermodynamics perspective. By following Thagard (2012) and Love (2013), we presented each perspective as a core reasoning and a question agenda that represented the thinking patterns that belong to the perspective at hand.

In this article, we propose "chemical perspectives" as an alternative way for organizing chemistry curricula. The four chemical perspectives that we propose, encompass various aspects of the frameworks that we discussed earlier, but elaborated and integrated in a distinctive way. Many current chemistry curricula are for example organized around lists of specific concepts. In a perspective-based framework, these specific concepts are organized around chemical core ideas, similar to the big ideas and threshold concepts frameworks. A perspective-based chemistry curriculum as envisioned in this paper, however, differs from these frameworks by emphasizing that students should also learn to use these big ideas for asking questions, model development et cetera.

The ambition to combine core ideas with this type of scientific practices is also central to the NGSS framework and chemistry curricula inspired by this framework (Cooper et al. 2017; Stowe et al. 2019). These frameworks propose to explicitly combine core ideas with scientific practices. However, both frameworks elaborate scientific practices on a rather abstract level, as we discussed in Sects. 2.3 and 2.4, and do not specify the type of chemical questions that can be asked, the types of possible answers that can be formulated and how these can combined and applied to develop a specific model for explaining a chemical phenomenon. Such perspective-based ways of chemical thinking are also not specified in the styles of reasoning framework. In sum, in our perspective-based framework, chemical ideas, and practices are not separated as in many regular chemistry curricula, nor combined as in NGSS-inspired chemistry curricula. Instead, core ideas and practices are elaborated and integrated in distinct chemical ways of thinking characterized by a core reasoning pattern and a related question agenda.

This study has three important limitations that should be addressed in future research. The first limitation concerns the Dutch context of the study. Although international chemistry curriculum frameworks were discussed, we limited our study to Dutch chemistry textbooks and syllabi and Dutch chemistry teachers. The second limitation concerns the four chemical perspectives that we propose.

In this study, we focused on the potential of chemical perspectives for developing ways of thinking that help explain and hypothesize about phenomena. However, as well as explaining 
phenomena, chemists also analyze and synthesize (Evans et al. 2006; Goedhart 2007). In another project, we investigated thinking patterns that belong to all the various purposes of chemistry and connected them to ways of thinking about the design of chemical experiments. Furthermore, we addressed in this paper examples of how the chemical perspectives can be used to think about fundamentally chemical problems. We contend that curricula based on perspectives have a much broader potential. Chemical perspectives could be combined with perspectives of other domains, such as for example physics, economy or psychology, to address socially relevant multidisciplinary problems such as our dependence on fossil fuel. Students could develop domain specific perspectives as complementary thinking tools for addressing such issues, making visible the power and limitations of every perspective, including chemical perspectives. This way, a chemistry curriculum based on perspectives would contribute to specific dimensions of "chemical literacy" (Shwartz et al. 2005), i.e., to understanding the nature of chemistry, its relevance, applications, and limitations. This line of thought also connects to the work of Mahaffy et al. (2019) who propose a systems thinking approach to create a more holistic chemistry curriculum. The authors show by means of the Haber-Bosch reaction, that is generally taught as a rather isolated topic, how systems thinking can be used to place a chemical process like this in a broader, meaningful context of sustainability, by identifying relevant sub-systems (e.g., renewable natural resources). We contend that this allows for combing chemical perspectives productively with perspectives from other domains, including more technological ones (such as ecology or food production) to emphasize their complementary nature. Different research initiatives are being developed in this direction in the Netherlands; however, more research is needed as to how this can be productively done in secondary education.

The third limitation concerns using chemical perspectives as an organizing principle for the secondary-school (pre-university) chemistry curriculum. We focused on the potential of chemical perspectives as organizers for the chemistry curriculum (analogous to Osborne et al. 2018). Identifying the chemical perspectives is a first step in the development of a

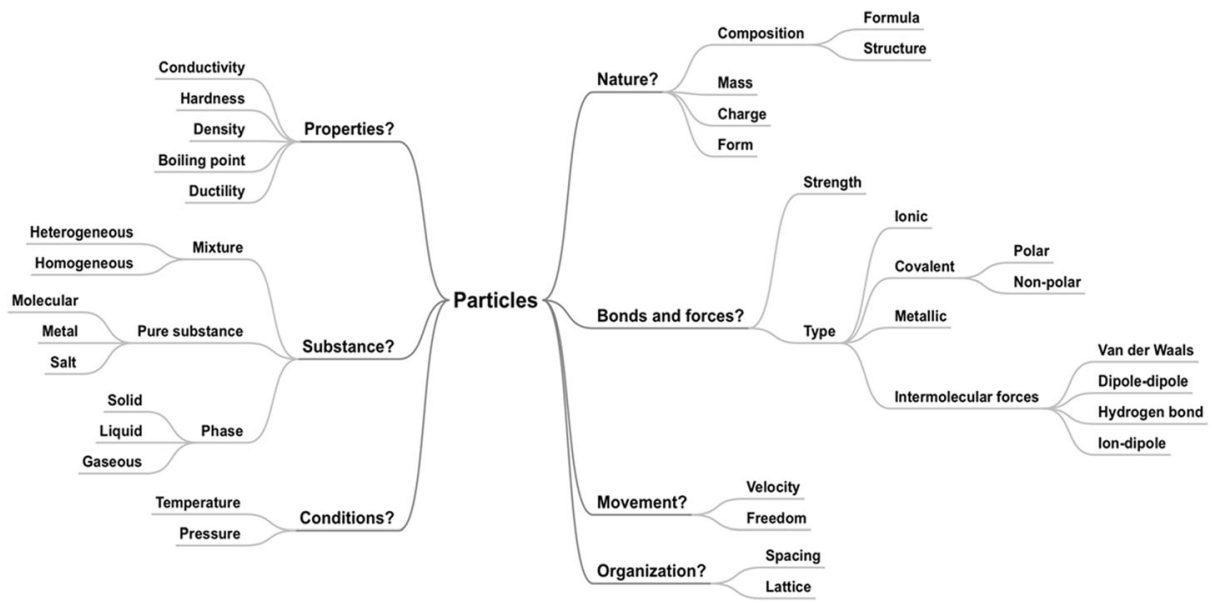

Fig. 2 Extended version of the particle perspective at the level of secondary-school chemistry education. The lines of inquiry of a given perspective function as an organizing principle. Each of the key questions of the question agenda for a particle perspective - in fact, the core reasoning - is extended with different possible options. The different forces that hold particles together are now the different values the more general branch "forces" can take. This allows a hierarchy of concepts to emerge 
curriculum model for a, secondary-school (pre-university) chemistry curriculum. A next step would be to develop learning progressions that are based on the perspectives. For this, we can draw on work of different scholars, for example, of Keith Taber who in a recent publication thoroughly discusses the conceptual nature of chemistry and reviews the specific difficulties that students encounter when learning chemistry (Taber 2019). Such work informs the development of learning progressions (see also Merritt and Krajcik 2013). Furthermore, standards need to be developed, and ways to assess chemical ways of thinking. Three promising methods for assessing domain specific ways of thinking have been developed and tested elsewhere (see Den Otter et al., submitted).

We also did not try to determine which pedagogies teachers could use to support students with mastering chemical perspectives as thinking tools, although some guidelines inevitably came to the fore. Neither did we seek to establish ways to assess domain-
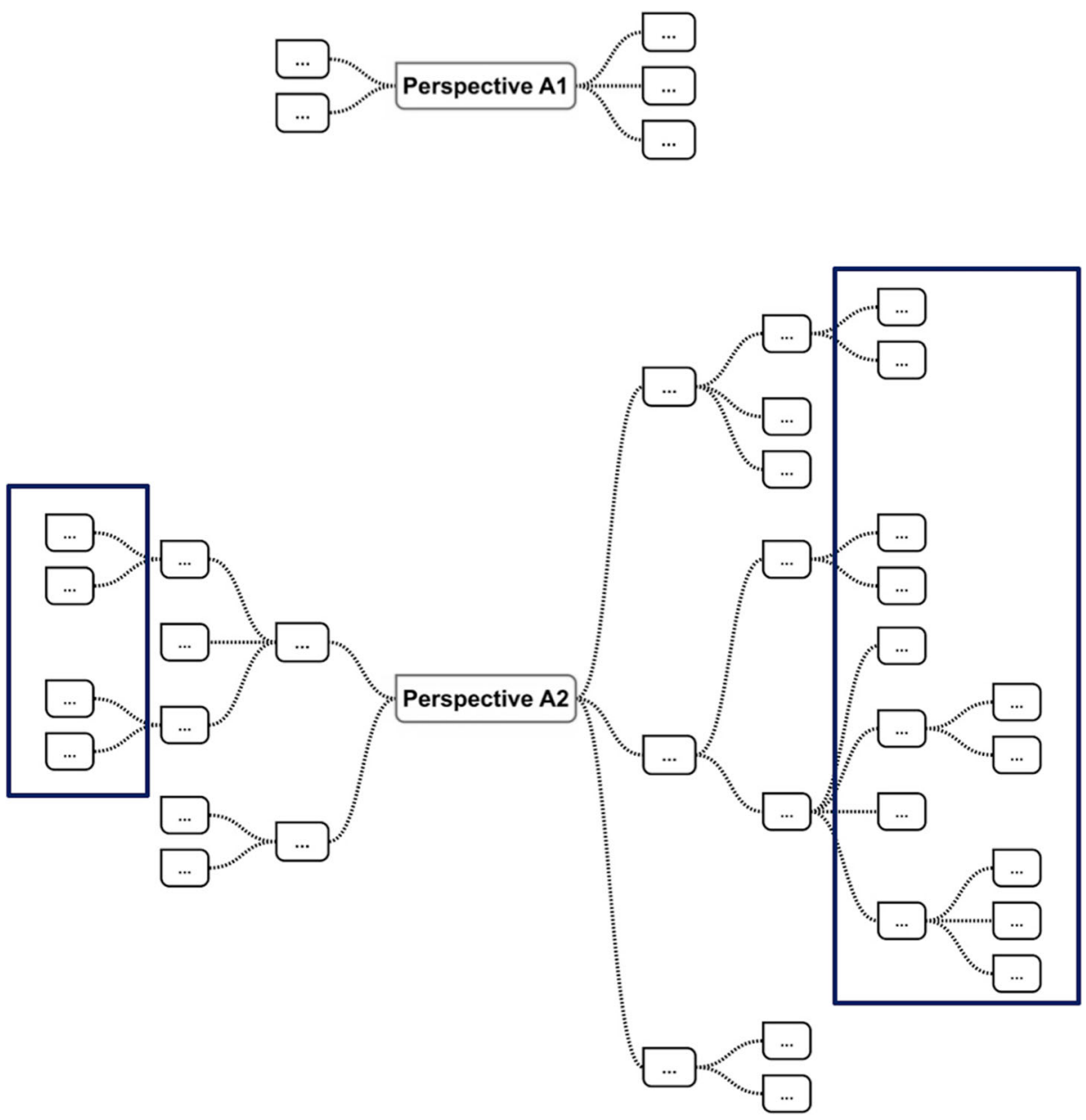

Fig. 3 A perspective as a hierarchical organizing principle. Perspectives A1 and A2 show how the core reasoning and accompanying basic question agenda (lines of inquiry) determine what the core explanatory model is (A1) and what cases are (A2). Chemistry curricula standards generally consist of lists of general skills (e.g., reasoning skills) and fragmented lists of concepts (marked here by the squares) 
specific ways of thinking. These challenging questions are currently being addressed in other research projects in the same research program. One design-based research project, for example, is examining how secondary-school students can be supported in developing ecological ways of thinking. A follow-up to the present study is investigating the design guidelines that teachers can use to assess the quality of their students' chemical ways of thinking, as, to a great extent, what is taught and learned is determined by what is assessed (Taber 2008).

In conclusion, we hope that this contribution inspires those in the field to further explore the options for and implications of envisioning the development of domain-specific perspectives as curriculum organizers, so that students develop not only a deeper understanding of domainspecific ways of thinking but also their potential as thinking tools.

\section{Compliance with ethical standards}

Conflict of interest The authors declare that they have no conflict of interest

Open Access This article is licensed under a Creative Commons Attribution 4.0 International License, which permits use, sharing, adaptation, distribution and reproduction in any medium or format, as long as you give appropriate credit to the original author(s) and the source, provide a link to the Creative Commons licence, and indicate if changes were made. The images or other third party material in this article are included in the article's Creative Commons licence, unless indicated otherwise in a credit line to the material. If material is not included in the article's Creative Commons licence and your intended use is not permitted by statutory regulation or exceeds the permitted use, you will need to obtain permission directly from the copyright holder. To view a copy of this licence, visit http://creativecommons.org/licenses/by/4.0/.

\section{References}

Atkins, P. (2010). Chemistry's core ideas. Chemistry education in New Zealand, 8-12. http://nzic.org. nz/chemed-nz/issue-archive/ChemEdNZ_Aug_2010_Atkins.pdf. Accessed 12 Nov 2017.

Brigandt, I. (2013). Explanation in biology: Reduction, pluralism, and explanatory aims. Science \& Education: Contributions from History, Philosophy and Sociology of Science and Mathematics, 22(1), 69-91.

Callebaut, W. (2012). Scientific perspectivism. Studies in History and Philosophy of Science Part C, 43(1), 6980.

Cambridge International Examinations (2016). Cambridge International AS \& A Level: Chemistry Syllabus.

Claesgens, J., Scalise, K., Wilson, M., \& Stacy, A. (2009). Mapping student understanding in chemistry: The perspectives of chemists. Science Education, 93, 56-85. https://doi.org/10.1002/sce.20292.

Cooper, M. M., Posey, L. A., \& Underwood, S. M. (2017). Core ideas and topics: Building up or drilling down? Journal of Chemistry Education, 94(5), 541-548.

Crombie, A. C. (1994). Styles of scientific thinking in the European tradition: The history of argument and explanation especially in the mathematical and biomedical sciences and arts (Vol. 1). London: Duckworth.

de Jong, O., \& Talanquer, V. (2015). Why is it relevant to learn the big ideas in chemistry at school? In I. Eilks \& A. Hofstein (Eds.), Relevant chemistry education - From theory to practice (pp. 11-31). Boston: Sense Publishers.

Erduran, S. (2007). Breaking the law: Promoting domain-specificity in chemical education in the context of arguing about the periodic law. Foundations of Chemistry, 9, 247-263.

Evans, K. L., Leinhardt, G., Karabinos, M., \& Yaron, D. (2006). Chemistry in the field and chemistry in the classroom: A cognitive disconnect. Journal of Chemistry Education, 83, 655-661.

Gabbay, D. M., Thagard, P., \& Woods, J. (2010). Philosophy of chemistry. In Handbook of the philosophy of science (Vol. 6, 1st ed.). Elsevier.

Giere, R. N. (2010). Scientific perspectivism. Chicago: University of Chicago Press.

Gilbert, J. K. (2006). On the nature of context in chemical education. International Journal of Science Education, 28(9), 957-976. 
Gillespie, R. J. (1997). The great ideas of chemistry. Journal of Chemistry Education, 74(7), 862. https://doi. org/10.1021/ed074p862.

Goedhart, M. (2007). A new perspective on the structure of chemistry as a basis for the undergraduate curriculum. Journal of Chemistry Education, 84, 971-976.

Hintikka, J. (2007). Socratic epistemology: Explorations of knowledge-seeking by questioning. Cambridge: Cambridge University Press.

Kind, P., \& Osborne, J. (2017). Styles of scientific reasoning: A cultural rationale for science education? Science Education, 101, 8-31.

Kuipers, T. A. (2007). Laws, theories and research programs. In D. M. Gabbay, P. Thagard, J. Woods, \& T. A. Kuipers (Eds.), General philosophy of science: Focal issues (pp. 1-97). Amsterdam: Elsevier.

Love, A. (2013). Interdisciplinary lessons for the teaching of biology from the practice of evo-devo. Science \& Education: Contributions from History, Philosophy and Sociology of Science and Mathematics, 22(2), 255278.

Mahaffy, P. G., Matlin, S. A., Holme, T. A., \& MacKellar, J. (2019). Systems thinking for education about the molecular basis of sustainability. Nature Sustainability, 2(5), 362-370.

Merritt, J., \& Krajcik, J. (2013). Learning progression developed to support students in building a particle model of matter. In G. Tsaparlis \& H. Sevian (Eds.), Innovations in science education and technology. Concepts of matter in science education (pp. 11-45). Dordrecht: Springer Netherlands.

Meyer, J. H. F., \& Land, R. (2003). Threshold concepts and troublesome knowledge: Linkages to ways of thinking and practising. In C. Rust (Ed.), Improving student learning - theory and practice ten years on (pp. 412-424). Oxford: Oxford Centre for Staff and Learning Development (OCSLD).

National Research Council (NRC). (2013). The next generation science standards. Washington, D.C.: The National Academies Press.

NGSS Lead States. (2013). Next Generation Science Standards: For States, By States. Washington, DC: National Academies Press.

Ohlsson, S. (2013). Deep learning how the mind overrides experience. Cambridge: Cambridge University Press.

Osborne, J., Rafanelli, S., \& Kind, P. (2018). Toward a more coherent model for science education than the crosscutting concepts of the next generation science standards: The affordances of styles of reasoning. Journal of Research in Science Teaching, 55(7), 962-981. https://doi.org/10.1002/tea.21460.

Rescher, N. (2008). Ontology in cognitive perspective. Axiomathes, 18(1), 25-36.

Sevian, H., \& Talanquer, V. (2014). Rethinking chemistry: A learning progression on chemical thinking. Chemistry Education Research and Practice, 15, 10-23.

Shwartz, Y., Ben-Zvi, R., \& Hofstein, A. (2005). The importance of involving high-school chemistry teachers in the process of defining the operational meaning of 'chemical literacy. International Journal of Science Teaching, 27(3), 323-344.

Stowe, R. L., Herrington, D. G., McKay, R. L., \& Cooper, M. M. (2019). The impact of Core-idea centered instruction on high school students' understanding of structure-property relationships. Journal of Chemistry Education, 96(7), 1318-1326. https://doi.org/10.1021/acs.jchemed.9b00071.

Taber, K. S. (2008). Towards a curricular model of the nature of science. Science \& Education, 17(2-3), 179218. https://doi.org/10.1007/s11191-006-9056-4.

Taber, K. S. (2019). The nature of the chemical concept: Constructing chemical knowledge in teaching and learning. Cambridge: Royal Society of Chemistry.

Talanquer, V. (2015). Threshold concepts in chemistry: The critical role of implicit schemas. Journal of Chemistry Education, 92(1), 3-9.

Talanquer, V. (2016). Central ideas in chemistry: An alternative perspective. Journal of Chemistry Education, 93(1), 3-8.

Talanquer, V., \& Pollard, J. (2010). Let's teach how we think instead of what we know. Chemistry Education Research and Practice, 11, 74-83.

Thagard, P. (2012). The cognitive science of science: Explanation, discovery and conceptual change. Cambridge: MIT Press.

The College Board. (2014). AP chemistry course and exam description.pdf. http://media.collegeboard.com/. Accessed 10 Jan 2019.

Van Berkel, B., De Vos, W., Verdonk, A., \& Pilot, A. (2000). Normal science education and its dangers: The case of school chemistry. Science \& Education, 9, 123-159.

Weisberg, M., Needham, P., \& Hendry, R. (2016). Philosophy of chemistry. In: E.N. Zalta (ed.) The Stanford encyclopedia of philosophy (winter 2016 edition). https://plato.stanford.edu/archives/win2016 /entries/chemistry

Wimsatt, W. C. (2007). Re-engineering philosophy for limited beings: Piecewise approximations to reality. Cambridge: Harvard University Press. 
Windschitl, M., Thompson, J., \& Braaten, M. (2008). Beyond the scientific method: Model-based inquiry as a new paradigm of preference for school science investigations. Science Education, 92(5), 941-967.

Zumdahl, S. S., \& Zumdahl, S. L. (2006). Chemistry. Hampshire: Cengage Learning, Inc..

Publisher's Note Springer Nature remains neutral with regard to jurisdictional claims in published maps and institutional affiliations.

\section{Affiliations}

\section{Ilse Landa ${ }^{1} \cdot$ Hanna Westbroek ${ }^{1} \cdot$ Fred Janssen $^{2} \cdot$ Jacqueline van Muijlwijk $^{3} \cdot$ Martijn Meeter ${ }^{1}$}

1 Graduate School of Education, LEARN! Research Institute, Vrije Universiteit Amsterdam, Van der Boechorststraat 7, 1081 BT Amsterdam, The Netherlands

2 ICLON, Leiden University Graduate School of Teaching, Wassenaarseweg 62A, 2333 AL Leiden, The Netherlands

3 AIMMS, Faculty of Sciences, Vrije Universiteit Amsterdam, de Boelelaan 1083, 1081 HV Amsterdam, The Netherlands 